\title{
The effects of intermittent hypoxia training on hematological and aerobic performance in triathletes
}

\author{
DJ Ramos-Campo ${ }^{1,2}$, F Martínez-Sánchez ${ }^{2}$, P Esteban-García ${ }^{2}$, JA Rubio-Arias ${ }^{1,2}$, \\ VJ Clemente-Suarez ${ }^{3}$, JF Jiménez-Díaz ${ }^{2}$ \\ ${ }^{1}$ Department of Physical Activity and Sport Science, Sport Science Faculty, \\ Catholic University of Murcia, Murcia, Spain \\ ${ }^{2}$ Laboratory of Physical Performance and Readaptation Injuries, \\ University of Castilla-La Mancha, Toledo, Spain \\ ${ }^{3}$ Department of Motricity, Human Performance and Sport Management, \\ European University of Madrid, Madrid, Spain
}

Received: June 4, 2014

Accepted: August 3, 2015

\begin{abstract}
The aim of the present research was to analyze modifications on hematological and aerobic performance parameters after a 7-week intermittent hypoxia training (IHT) program. Eighteen male trained triathletes were divided in two groups: an intermittent hypoxia training group (IHTG: $n$ : 9; $26.0 \pm 6.7$ years; $173.3 \pm 5.9 \mathrm{~cm} ; 66.4 \pm 5.9 \mathrm{~kg}$; $\mathrm{VO}_{2}$ max: $59.5 \pm 5.0 \mathrm{ml} / \mathrm{kg} / \mathrm{min}$ ) that conducted a normoxic training plus an IHT and a control group (CG: $n: 9 ; 29.3$ \pm 6.8 years; $174.9 \pm 4.6 \mathrm{~cm} ; 59.7 \pm 6.8 \mathrm{~kg} ; \mathrm{VO}_{2} \max : 58.9 \pm 4.5 \mathrm{ml} / \mathrm{kg} / \mathrm{min}$ ) that performed only a normoxic training. Training process was standardized across the two groups. The IHT program consisted of two 60 -min sessions per week at intensities over the anaerobic threshold and atmospheric conditions between 14.5 and $15 \% \mathrm{FiO}_{2}$. Before and after the 7-week training, aerobic performance in an incremental running test and hematological parameters were analyzed. After this training program, the IHTG showed higher hemoglobin and erythrocytes $(p<0.05)$ values than in the CG. In terms of physiological and performance variables, between the two groups no changes were found. The addition of an IHT program to normoxic training caused an improvement in hematological parameters but aerobic performance and physiological variables compared to similar training under normoxic conditions did not increase.

Keywords: intermittent hypoxic training (IHT), maximal oxygen uptake, triathlon, hematocrit, erythropoiesis
\end{abstract}

The concept of altitude or hypoxic training is a common technique used by athletes to improve their aerobic capacity and endurance performance in competition (6). Several strategies of altitude training, like "live high-train high" (LHTH) or "live high-train low" (LHTL) have been proposed (29). They are based on adaptive changes of humans to chronic hypoxia (14). Chronic exposure to altitude improves oxygen transport capacity by enhancing erythropoietin secretion and hemoglobin mass and enhancing maximal oxygen uptake $\left(\mathrm{VO}_{2} \mathrm{max}\right)$ and exercise performance (6). During the last years several intermittent hypoxia strategies, such as the intermittent hypoxia training (IHT), have been used to increase the athletes' sea level performance (18). In this method, athletes live in normoxic conditions and train in hypoxic environment (18).

Hypoxia training produces changes in biochemical and skeletal muscle systems. This fact increases the oxygen transport capacity of blood, due to the increase in erythropoietin

Corresponding author: Dr Domingo Jesús Ramos-Campo

Catholic University of Murcia (UCAM)

Los Jerónimos Road 135, Guadalupe (Murcia) 30107, Spain

Phone: (+34) 9682788 01; Fax: (+34) 9682786 48; E-mail: domingojesusramos@gmail.com 
hormone (EPO), hemoglobin $(\mathrm{Hb})$ and erythrocytes, which improve both oxidative metabolism $(15,31)$ and anaerobic performance (12) due to an increase in muscle buffer capacity (10) and an increase in the enzymes activity (21).

There is a controversy regarding the efficacy of hypoxic training since several authors have reported improvements in aerobic performance $(17,31)$, while others have found only maintenance of performance $(20,24,27)$. Specifically in triathletes, Vallier et al. (28) found that IHT increased physical performance without modifying maximal oxygen uptake $\left(\mathrm{VO}_{2} \max \right)$ or EPO. In contrast, Meeuwsen et al. (17) observed an increase in hematocrit, $\mathrm{Hb}$, $\mathrm{VO}_{2}$ max and average power in a Wingate test conducted after an IHT. Hendriksen and Meeuwsen (12) using the same protocol found a maintenance in the $\mathrm{VO}_{2}$ max and the peak power in a $20-\mathrm{km}$ cycle ergometer test and an increase in the average power and peak power in a Wingate test. Furthermore, Roels et al. (23) measured an increase in average power in a 10 -min cycle ergometer test, with concomitant increases in $\mathrm{VO}_{2}$ max and maintenance of cycling economy.

The effect of IHT in sport performance is influenced by the training protocol, the type of hypoxia (normobaric or hypobaric), the duration and intensity of the training program, the number of hypoxia sessions per week and the simulated altitude (18). The effects of IHT also depend on the training level, since athletes with lower training levels, achieve higher improvements in performance than high-performance athletes do (16).

The results of the effectiveness of IHT improving $\mathrm{VO}_{2}$ max and endurance performance at sea-level are ambiguous (6) due to methodological differences in the studies. Then, further studies are needed to evidence the effectiveness of IHT.

Consequently, the aim of the present research was to analyze changes in hematological parameters and aerobic performances after a 7-week IHT program in competitive triathletes. It was hypothesized that IHT would increase both hematological parameters and aerobic performance of triathletes compared to normoxic training.

\section{Materials and Methods}

A pre-post randomized controlled training intervention design was employed to analyze the effect of an IHT program on hematological parameters and aerobic performance in trained triathletes. Participants were randomly divided into two groups: the first group performed a normoxic training during a 7-week period, while the second group conducted an IHT program along with the normoxic training during a 7-week period. Training process was standardized in the two groups.

\section{Participants}

We analyzed 18 male elite triathletes divided randomly in two groups: an intermittent hypoxia training group (IHTG) $(n$ : 9; age: $26.0 \pm 6.7$ years; height: $173.3 \pm 5.9 \mathrm{~cm}$; weight: $66.4 \pm 5.9$ $\mathrm{kg}$; fat mass: $13.3 \pm 2.0 \%$; $\mathrm{VO}_{2} \max : 59.5 \pm 5.0 \mathrm{ml} / \mathrm{kg} / \mathrm{min}$ ) in which each athlete conducted their usual normoxic training plus an IHT program, and a control group (CG) ( $n$ : 9; age: 29.3 \pm 6.8 years; height: $174.9 \pm 4.6 \mathrm{~cm}$; weight: $71.6 \pm 6.8 \mathrm{~kg}$; fat mass: $13.5 \pm 2.7 \%$; $\mathrm{VO}_{2} \max$ : $58.9 \pm 4.5 \mathrm{ml} / \mathrm{kg} / \mathrm{min}$ ) in which each athlete performed their usual normoxic training. The study was designed in compliance with the recommendations for clinical research of the Helsinki Declaration of the World Medical Association. The protocol was reviewed and approved by the local ethics committee. 


\section{Procedures}

Hematological and performance tests were conducted before and after the 7-week training period. Hematological tests were conducted by the triathletes fasted in a laboratory with ISO 9001:2008 and 15189:2007 accreditation. The blood sample $(2.5 \mathrm{ml})$ was withdrawn from an antecubital vein using a sterile technique to analyze hematological variables. Blood samples were taken before breakfast after an overnight fast. Blood extraction was performed with the subject seated and after a rest day. The hematological variables of erythrocytes $\left(\times 10^{6} / \mu \mathrm{l}\right), \mathrm{Hb}$ $(\mathrm{g} / \mathrm{dl})$, hematocrit $(\%)$ and reticulocytes (number/ $\mu \mathrm{L})$ were analyzed immediately from the blood sample using a System 9000 hematology Coulter counter (Menarini Diagnostics, Spain). EPO ( $\mathrm{mU} / \mathrm{ml})$ was estimated in serum of the blood samples by radioimmunoassay using Incstar radioimmuno analyzer (Incstar, Diasorin, Madrid, Spain). The intra-interassay coefficient of variations were $<1.5 \%$ in erythrocytes, $\mathrm{Hb}$, hematocrit measurements and $<1.8 \%$ in reticulocytes and EPO.

Subsequently, three hours after standardized breakfast, triathletes conducted a maximal incremental running treadmill test: a 5-min warm-up at $8 \mathrm{~km} / \mathrm{h}$ with a $1 \%$ incline, followed by increases of $1 \mathrm{~km} / \mathrm{h}$ per minute until exhaustion, according to previous literature (4). Ventilatory thresholds (VT1 and VT2) were estimated according to the proposal of Skinner and McLellan (26) and $\mathrm{VO}_{2}$ max was considered to be reached according to traditional physiological criteria set by Howley et al. (13): (i) occurrence of a plateau despite an increase in speed; (ii) elevated blood lactate concentration ( $\geq 8 \mathrm{mmol} / \mathrm{l})$; (iii) elevated respiratory exchange ratio ( $\mathrm{r} \geq 1.0$ ); (iv) elevated heart rate ( $\geq 90 \%$ of $[220$-age]); and (v) maximal perceived exertion, controlled visually and on a case-by-case basis. The incremental running test was performed on an HP Saturn treadmill (H/P/Cosmos 3P 4.0 R, H/P/Cosmos Sports \& Medical, Nussdorf-Traunstein, Germany). An Ultima CPX gas analyzer (Medical Graphics, St. Paul, USA) and a Cardioperfect electrocardiograph (Welch Allyn Inc., Skaneateles Falls, USA) were used to obtain the variables of absolute $\mathrm{VO}_{2} \max (\mathrm{ml} / \mathrm{min})$, relative $\mathrm{VO}_{2} \mathrm{max}(\mathrm{ml} /$ $\mathrm{kg} / \mathrm{min})$, oxygen consumption at VT1 $(\mathrm{ml} / \mathrm{kg} / \mathrm{min})$ and at VT2 $(\mathrm{ml} / \mathrm{kg} / \mathrm{min})$, heart rate $(\mathrm{HR})$ (bpm) and speed $(\mathrm{km} / \mathrm{h})$ at VT1, VT2 and $\mathrm{VO}_{2}$ max and total duration of treadmill test (s).

To conduct the hypoxic training sessions, a $\mathrm{GO}_{2}$ altitude Hypoxicator (Biomedtech Australia, Melbourne, Australia) with two 120-1 Douglas bags and a suitable mask were used. The training sessions were registered in watts and controlled by a Monark 839E (Monark Exerc., Vansbo, Sweden) ergometer.

\section{Training program}

The day after completion of the pre-tests triathletes began the 7-week training period, the IHTG conducted an IHT protocol twice per week during the 7-week period combining continuous and interval training methods, in which the percentage of oxygen in the inspired air gradually decreased and the session length remained stable (60 min) (18). The characteristics of the IHT program are shown in Table I. The intensity of the hypoxia training sessions was established for each individual based on a hypoxia test conducted prior to starting the training program, consisting of an incremental cycling test: 5-min warm-up at 75 watts, followed by increases of 50 watts per minute until exhaustion (3). Cycling cadence during the test was maintained between 90-105 rpm. During the last 15 seconds of each work-load, heart rate (HR) and rating of perceived exertion (RPE) were measured. 
Table I. Intermittent hypoxia training program characteristics

\begin{tabular}{|c|c|c|c|c|c|c|c|c|c|c|}
\hline Week & Session & $\begin{array}{c}\text { Dura- } \\
\text { tion } \\
\text { (min) }\end{array}$ & $\begin{array}{c}\text { Inten- } \\
\text { sity } \\
(\%)\end{array}$ & $\begin{array}{l}\text { Training } \\
\text { method }\end{array}$ & $\begin{array}{l}\text { Session } \\
\text { trimps } \\
\text { IHTG }\end{array}$ & $\begin{array}{c}\text { Session } \\
\text { trimps } \\
\text { CG }\end{array}$ & $p$ & $\begin{array}{l}\text { Weekly } \\
\text { trimps } \\
\text { IHTG }\end{array}$ & $\begin{array}{c}\text { Weekly } \\
\text { trimps } \\
\text { CG }\end{array}$ & $\begin{array}{l}\mathrm{FiO}_{2} \\
(\%)\end{array}$ \\
\hline \multicolumn{11}{|c|}{ Pre-test } \\
\hline \multirow{2}{*}{1} & 1 & 60 & 60 & Continuous & $84.6 \pm 7.2$ & $83.5 \pm 4.8$ & 0.934 & \multirow{2}{*}{$\begin{array}{c}1248.8 \pm \\
81.7\end{array}$} & \multirow{2}{*}{$\begin{array}{c}1244.4 \pm \\
53.5\end{array}$} & \multirow{8}{*}{$n$} \\
\hline & 2 & 60 & 65 & Continuous & $90.6 \pm 6.8$ & $94.4 \pm 4.7$ & 0.697 & & & \\
\hline \multirow{2}{*}{2} & 1 & 60 & 70 & Continuous & $96.5 \pm 6.4$ & $94.4 \pm 3.9$ & 0.431 & \multirow{2}{*}{$\begin{array}{c}1258.9 \pm \\
82.3\end{array}$} & \multirow{2}{*}{$\begin{array}{c}1254.5 \pm \\
53.9\end{array}$} & \\
\hline & 2 & 60 & $50-85$ & Interval & $107.5 \pm 8.7$ & $106.4 \pm 5.9$ & 0.768 & & & \\
\hline \multirow{2}{*}{3} & 1 & 60 & 70 & Continuous & $95.3 \pm 6.3$ & $94.6 \pm 4.3$ & 0.785 & \multirow{2}{*}{$\begin{array}{c}971.9 \pm \\
69.1\end{array}$} & \multirow{2}{*}{$\begin{array}{c}964.0 \pm \\
41.1\end{array}$} & \\
\hline & 2 & 60 & $50-85$ & Interval & $108.1 \pm 9.6$ & $106.6 \pm 6.3$ & 0.701 & & & \\
\hline \multirow{2}{*}{4} & 1 & 60 & 70 & Continuous & $98.7 \pm 6.3$ & $97.8 \pm 4.7$ & 0.746 & \multirow{2}{*}{$\begin{array}{c}961.4 \pm \\
59.5\end{array}$} & \multirow{2}{*}{$\begin{array}{c}959.8 \pm \\
37.1\end{array}$} & \\
\hline & 2 & 60 & 60 & Continuous & $83.9 \pm 7.8$ & $83.6 \pm 5.1$ & 0.913 & & & \\
\hline \multirow{2}{*}{5} & 1 & 60 & 60 & Continuous & $98.1 \pm 6.2$ & $97.3 \pm 4.6$ & 0.786 & \multirow{2}{*}{$\begin{array}{c}1046.4 \pm \\
69.9\end{array}$} & \multirow{2}{*}{$\begin{array}{c}1037.0 \pm \\
48.9\end{array}$} & \multirow{6}{*}{$\stackrel{n}{ \pm}$} \\
\hline & 2 & 60 & 65 & Continuous & $102.6 \pm 5.9$ & $102.2 \pm 5.3$ & 0.890 & & & \\
\hline \multirow{2}{*}{6} & 1 & 60 & $50-85$ & Interval & $114.8 \pm 8.9$ & $113.6 \pm 6.3$ & 0.754 & \multirow{2}{*}{$\begin{array}{c}991.5 \pm \\
57.2\end{array}$} & \multirow{2}{*}{$\begin{array}{c}985.8 \pm \\
44.7\end{array}$} & \\
\hline & 2 & 60 & 65 & Continuous & $98.7 \pm 6.6$ & $98.4 \pm 5.5$ & 0.895 & & & \\
\hline \multirow{2}{*}{7} & 1 & 60 & 65 & Continuous & $99.9 \pm 4.2$ & $98.9 \pm 5.1$ & 0.656 & \multirow{2}{*}{$\begin{array}{c}821.3 \pm \\
53.2\end{array}$} & \multirow{2}{*}{$\begin{array}{c}815.0 \pm \\
39.4\end{array}$} & \\
\hline & 2 & 60 & 60 & Continuous & $95.6 \pm 6.4$ & $95.1 \pm 4.4$ & 0.851 & & & \\
\hline
\end{tabular}

Duration in min; Intensity in \% power output obtained in a hypoxia test; Interval sessions:

$10 \min 60 \%+8 \times(2: 30 \min 85 \%+2: 30 \min 50 \%)+10 \min 60 \%$

During the 7-week period, both training groups (IHTG and CG) performed the same training sessions in normoxia. The training process was standardized across the two groups, therefore, both groups did the same total training load. The training load of swimming, cycling and running sessions conducted by the triathletes was quantified each week using the Training Impulse (TRIMP) (2) method (Table I).

\section{Statistical analysis}

The SPSS statistical package (version 20.0; SPSS, Inc., Chicago, IL, USA) was used to analyze the data. Normality and homoscedasticity were checked using a Shapiro-Wilks test. A two-factor (group $\times$ sample) ANOVA repeated measures with Bonferroni post hoc test was used to compare the results. The threshold for significant difference was set at $p<0.05$ for all comparisons. 


\section{Results}

There were no significant differences in TRIMP values between the IHTG and the CG during the 7-week training period. After the 7-week training the IHTG showed significantly higher values in hemoglobin and erythrocytes than the CG $(p<0.05)$. The basal values of erythropoietin were higher in the CG than the IHTG $(p=0.038)$, but after completing the 7-week training program, the differences were not significant. Before and after the treatment, the erythrocyte concentration was higher in the IHTG than in the CG, but the differences were significant $(p=0.008)$ only after the IHT program. Levels of Hb were similar in the IHTG and the CG in the pre-sample, but after the training programs, the IHTG showed significantly higher values than the CG $(p=0.022)$ (Fig. 1). Besides an increase in erythrocytes, $\mathrm{Hb}$, hematocrit, reticulocytes and EPO was found in the IHTG after completion of the training program (Table II). By contrast, in the CG there was found a tendency to decreased values of these variables after the 7-week of training.
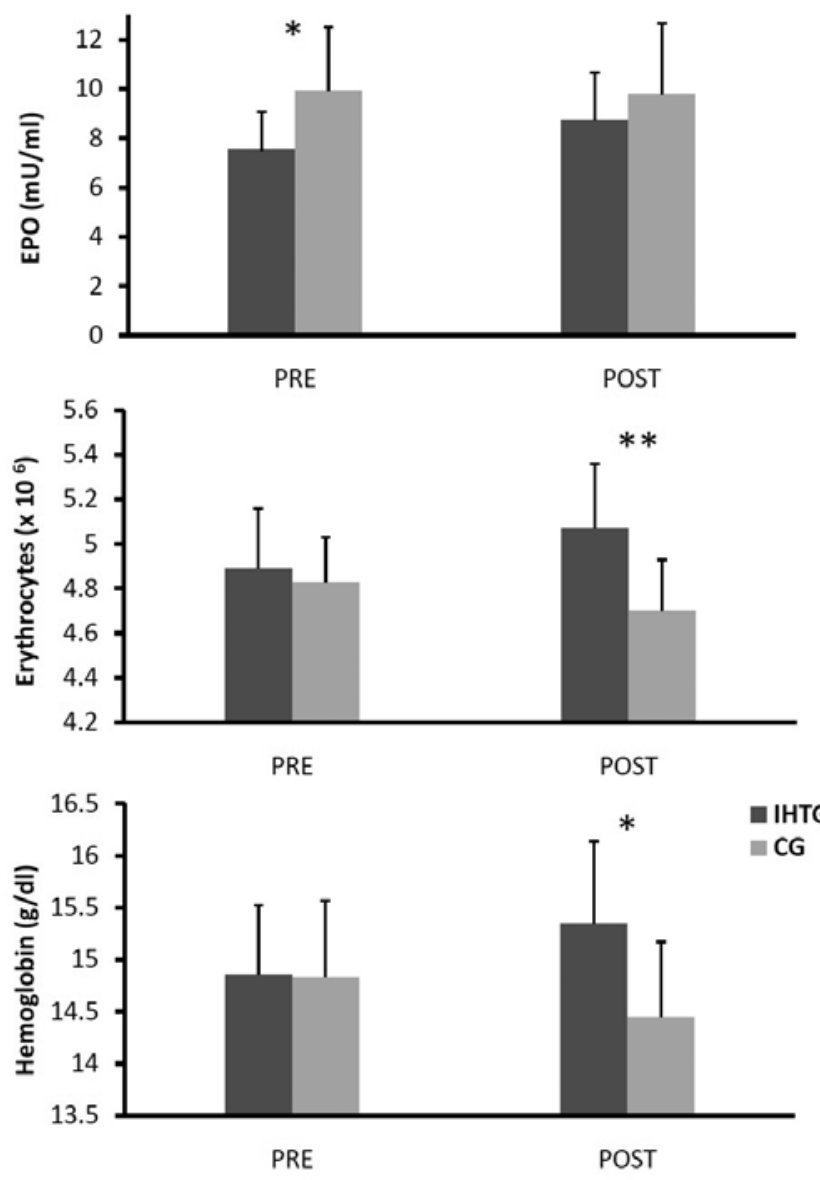

Fig. 1. Pre- and post-erythropoietin hormone, erythrocytes and hemoglobin values in IHTG and $\mathrm{CG}$.

$* p<0.05 ; * * p<0.01$; IHTG Intermittent hypoxia training group; CG - Control group 
Table II. Average values of hematologic variables

\begin{tabular}{|l|c|c|c|c|c|c|}
\hline \multicolumn{2}{|c|}{} & $\begin{array}{c}\text { Ery } \\
\left(\times \mathbf{1 0}^{6} / \boldsymbol{\mu} \mathbf{l}\right)\end{array}$ & $\begin{array}{c}\text { Hb } \\
(\mathbf{g} / \mathbf{d})\end{array}$ & $\begin{array}{c}\text { Htc } \\
(\mathbf{\%})\end{array}$ & $\begin{array}{c}\text { Ret } \\
(\mathbf{n} / \boldsymbol{\mu L})\end{array}$ & $\begin{array}{c}\text { EPO } \\
(\mathbf{m U} / \mathbf{m l})\end{array}$ \\
\hline \multirow{4}{*}{$\begin{array}{l}\text { IHTG } \\
(n=9)\end{array}$} & Pre & $4.9 \pm 0.3$ & $14.9 \pm 0.7$ & $44.1 \pm 2.4$ & $21562.5 \pm 8752.5$ & $7.5 \pm 1.6$ \\
\cline { 2 - 7 } & Post & $5.1 \pm 0.3$ & $15.4 \pm 0.8$ & $45.5 \pm 2.9$ & $35376.3 \pm 16859.7$ & $8.8 \pm 1.9$ \\
\cline { 2 - 7 } & $\%$ change & 3.7 & 3.3 & 3.1 & 64.1 & 16.6 \\
\cline { 2 - 7 } & $p$ & $0.039^{*}$ & $0.045^{*}$ & $0.045^{*}$ & $0.047^{*}$ & $0.049^{*}$ \\
\hline \multirow{4}{*}{$\begin{array}{l}\text { CG } \\
(n=9)\end{array}$} & Pre & $4.8 \pm 0.2$ & $14.8 \pm 0.7$ & $44.5 \pm 1.53$ & $32701.0 \pm 16529.4$ & $9.9 \pm 2.6$ \\
\cline { 2 - 7 } & Post & $4.7 \pm 0.2$ & $14.5 \pm 0.7$ & $44.1 \pm 2.20$ & $32688 \pm 23365.3$ & $9.8 \pm 2.9$ \\
\cline { 2 - 7 } & $\%$ change & -2.7 & -2.6 & -0.9 & -0.1 & -1.3 \\
\cline { 2 - 7 } & $p$ & 0.116 & 0.215 & 0.463 & 0.999 & 0.98 \\
\hline
\end{tabular}

$* p<0.05$; Ery - erythrocytes; Hb - hemoglobin; Htc - haematocrit; Ret - reticulocytes; EPO - erythropoietin hormone. IHTG - Intermittent hypoxia training group; CG - Control group

Table III summarizes the results of the incremental running test. No changes between groups were found in physiological and performance variables. Only the IHTG exhibited significant increases in absolute and relative $\mathrm{VO}_{2} \max$, running test time, VT1 and VT2, and significant decreases in HR at VT1 and VT2. The values of CG showed a significant increase in oxygen consumption at VT2 and decreased values of HR at VT1 and VT2.

\section{Discussion}

The purpose of the present study was to analyze changes in hematological parameters and the aerobic performance of trained triathletes before performing 7 weeks of either normoxic training or normoxic training plus an IHT. The initial hypothesis was not verified, since the IHTG showed a higher increase in hematological parameters than the CG after the 7-week training period, but the increase in aerobic performance was similar in both group

The efficacy of IHT depends on numerous variables, including duration, frequency, training protocol or simulated altitude (18). Millet et al. (18) recommend that intermittent hypoxia programs in elite athletes should be used during the competitive period, with two IHT sessions per week at a simulated altitude between 2500-3000 meters to develop the anaerobic threshold. These training sessions can also be complemented with three hours of IHE four or five times per week. The results obtained in the present study showed higher significant values in the IHTG than in the CG in hemoglobin and erythrocytes $(p<0.05)$. Besides, an increase in the number of red blood cells, $\mathrm{Hb}$, hematocrit, reticulocytes and EPO were found in the IHTG. However in the CG, these values remained close to baseline, with a tendency to decrease them. The decrease in these hematological parameters found in the CG was similar to that found in recent studies, in which authors measured decrease in hematological variables during the season when the training intensity and volume was higher (1). In contrast, during transition and no-training periods in professional cyclists, the opposite tendency was observed (19). Therefore, the implementation of IHT programs could prevent drops in hematological parameters during the training season. 


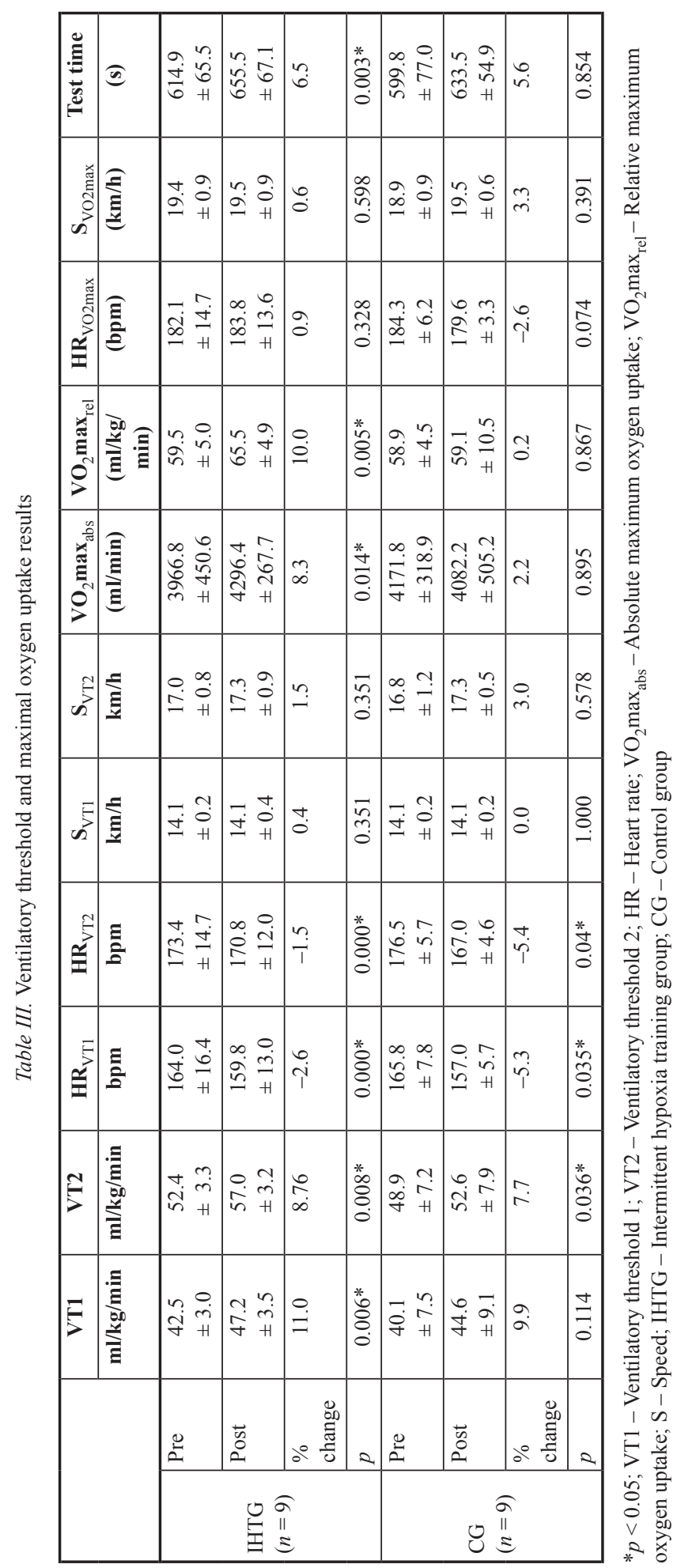


The increase in EPO found in the IHTG was in accordance with previous studies confirming the stimulatory effect of IHT on erythropoiesis (22). Along these lines, Eckardt et al. (8) found a significant increase in EPO after 5 hours of intermittent hypoxia exposure per day at 3000-4000 meters of altitude. Analyzing the effect of IHT on other hematological parameters, we found that our results were in agreement with the study of Hamlin et al. (11) which reported a similar increase in $\mathrm{Hb}$, hematocrit and reticulocytes. Moreover, other studies conducted in cyclists $(5)$, team sports players $(6,20)$ and swimmers $(27)$ did not find any change in blood parameters. Specifically, studies conducted on triathletes found contradictory results, as in the present study, increases in $\mathrm{Hb}$, erythrocytes and EPO were measured after a protocol of 10 sessions of $2 \mathrm{~h}$ at 2500 meters (17), but after 9 sessions of IHT at a simulated altitude of 4000 meters, values were unmodified (28). Moreover, previous results have shown that EPO secretion increases with and intermittent hypoxia stimulus. In this way, these increases are short-lived because metabolic acidosis caused by intense physical training produces a decrease of other parameters involved in the erythropoiesis (8). These widely divergent results may be due to the highly variable individual responses of the athletes in these studies, in which many participants may or may not respond and/or develop altitude acclimatization responses to the hypoxic programs. Additionally, other factors, such as simulated altitude, altitude simulation technology, hypoxia exposure time per session and the program duration, can influence the athletes' final response (22). Moreover, the different athletes' responses to IHT are most likely related to genetic factors (9), and in some cases, the effects are similar to those obtained by administration of exogenous erythropoietin (25).

Another important factor that can influence adaptive responses to hypoxic training was the training expertise of the athletes, as untrained subjects presented higher adaptation to conditions of reduced oxygen availability, whereas in highly trained athletes this adaptive response was smaller (22). Additionally, modulation and adaptation pathways of the oxygen transport system used to increase performance at sea level due to the increased ability to carry oxygen in the blood (31). However, the blood changes are usually small, as this is a system that rarely endures changes and requires a certain time to compensate and stabilize. The improvements in this system not only affect hematological parameters and athlete performance, they also improve the recovery processes after high training loads (18).

Theoretically, IHT can improve aerobic capacity and endurance performance at sea level through a series of adaptive changes, however, studies in the field of IHT are inconclusive $(7,31)$. The results of the present research showed no changes in physiological and performance variables in the experimental groups after the 7 weeks of training. Although there are no differences between groups, IHTG exhibited significant increases in absolute and relative $\mathrm{VO}_{2}$ max, running test time and oxygen consumption at VT1 and VT2. The values of CG showed a significant increase in oxygen consumption at VT2. These increases in performance agree with the studies of Dufour et al. (7) who found a significant increase in $\mathrm{VO}_{2}$ max and running speed in the VT2 after 6 weeks of hypoxic training, despite the absence of changes in hematological parameters. Similarly, Roels et al. (24) found a significant increase in $\mathrm{VO}_{2}$ max after an intensive hypoxia training without changes in hematological parameters, and Czuba et al. (5) found an increase in $\mathrm{VO}_{2} \max$, exercise time and average power in a 30-km cycle ergometer test after hypoxic training. On the other hand, in the study of Hendriksen and Meeuwsen (12) no improvements in $\mathrm{VO}_{2}$ max were found 10 days after 2-hour sessions at 2500 meters of simulated altitude and an intensity of $60-70 \%$ of the heart rate reserve. The principal reason why the previous authors did not find improvements in performance was that intensity used was not enough to produce improvements in aerobic capacity. These lack of improvements in aerobic capacity and endurance performance was 
due to the hypoxia-induced low intensity effort during the IHT workouts. Indeed, Czuba et al. (5) affirmed that an intensity of $60-70 \%$ of the heart rate reserve is not a sufficient training stimulus and will not lead to improvements in aerobic capacity. Regarding the test time, we measured an increase of $6 \%$ in the IHTG, a result in consonance with previous studies $(7,17$, 30 ) and that disagrees with another study that did not find an increase in this parameter (23). These differences in performance might be influenced by the initial athletic performance level of participants, as well as by the session duration, simulated altitude and intensity of hypoxia training (15). Therefore, intensities near to VT2 are recommended (7) as this intensity increases the oxidative capacity of muscles, provides a greater buffer capacity and muscle $\mathrm{pH}$ regulation and increases the production of monocarboxylate MCT 1 and MCT 4 transporters, which are responsible for the lactate transport through plasma membranes in the erythrocytes and skeletal muscle cells, resulting in enhanced athletic performance (31).

The IHTG presented a significant decrease in heart rate at VT1 and VT2 in the incremental running test after the IHT program. These results suggested a higher cardiac efficiency in the aerobic and anaerobic threshold areas, as triathletes were able to run with a slight speed in the VT1 and VT2 with a significantly lower heart rate (4). In addition, the hypothesis that hypoxia increases the $\mathrm{VO}_{2}$ max due to a stimulation of erythropoiesis was not corroborated because IHTG showed higher hematological variables than CG but the increase in physiological and aerobic performance variables was showed by both groups and there were no differences between them. Oxygen transport system adaptations are usually small because it is difficult to alter the system and the changes require a certain amount of time to occur and to stabilize. It is also important to highlight the improvement in this system that not only affects athletic performance, it also improves recovery and assimilation of high training loads, health, life quality and prevents diseases associated with altitude in athletes who use these specific training programs (18).

The most important finding of this work states that the implementation of an IHT program during 7 weeks, 60 min per session, 2 times per week at $14.5-15 \% \mathrm{FiO}_{2}$ together with normoxic training increased hematological variables of trained triathletes more than a normoxic training. These data suggest that an IHT protocol is an effective training to improve hematological parameters in triathletes. However, the program did not produce enhancements of aerobic capacity and performance of trained triathletes more than the normoxic training.

\section{Acknowledgement}

We would like to thank all the athletes for their collaboration in the study.

\section{REFERENCES}

1. Banfi G, Lundby C, Robach P, Lippi G: Seasonal variations of haematological parameters in athletes. Eur. J. Appl. Physiol. 111, 9-16 (2011)

2. Banister EW (1991): Modeling elite athletic performance. In: Physiological Testing of Elite Athletes, eds Green H, McDougal J, Wenger H, Champaign, Human Kinetics, pp. 403-424

3. Carig N, Walsh C, Martin D, Woolford S, Borudon P, Stanef T, Savage B (2000): Protocols for the Physiological Assessment of High-Performance Track, Road and Mountain Cyclist. In: Physiological Test for Elite Athletes, editors: Gore C, Champaign, Human Kinetics, pp. 258-277

4. Clemente-Suárez VJ, González-Ravé JM, Navarro-Valdivielso F: Short-term periodized aerobic training does not attenuate strength capacity or jump performance in recreational endurance athletes. Acta Physiol. Hung. $101,1-12(2014)$ 
5. Czuba M, Waskiewicz Z, Zajac A, Poprzecki S, Cholewa J, Roczniok, R: The effects of intermittent hypoxic training on aerobic capacity and endurance performance in cyclists. J. Sport Sci. Med. 10, 175-183 (2011)

6. Czuba M, Zajac A, Maszcyk A, Roczniok R, Poprzecki S, Garbaciak W, Zajac T: The effects of high intensity interval training in normobaric hypoxia on aerobic capacity in basketball players. J. Hum. Kinet. 39, $103-114$ (2013)

7. Dufour S, Ponsot E, Zoll J, Doutreleau S, Geny B, Lampert E, Billat V: Exercise training in normobaric hypoxia in endurance runners I. Improvement in aerobic performance capacity. J. Appl. Physiol. 100, 1238-1248 (2006)

8. Eckardt KU, Boutellier U, Kurtz A, Schopen M, Koller EA. Bauer C: Rate of erythropoietin formation in humans in response to acute hypobaric hypoxia. J. Appl. Physiol. 66, 1785-1788 (1989)

9. Gomez-Gallego F, Santiago C, Gonzalez-Freire M, Muniesa CA, Fernández Del Valle M, Pérez M, Lucía A: Endurance performance: genes or gene combinations? Int. J. Sports Med. 30, 66-72 (2009)

10. Gore CJ, Hahn AG, Aughey R, Martin D, Ashenden MJ, Clark SA: Live high-train low increases muscle buffer capacity and submaximal cycling efficiency. Acta Physiol. Scand. 173, 275-286 (2001)

11. Hamlin MJ, Marshall HC, Hellemans J, Ainslie N: Effect of intermittent hypoxia on muscle and cerebral oxygenation during a 20-km time trial in elite athletes: a preliminary report. Appl. Physiol. Nut. Metabol. 35, 548-559 (2010)

12. Hendriksen IJ, Meeuwsen T: The effect of intermittent training in hypobaric hypoxia on sea-level exercise: a cross-over study in humans. Eur. J. Appl. Physiol. 88, 396-403 (2003)

13. Howley ET, Basseet T, Welch HG: Criteria for maximal oxygen uptake: review and commentary. Med. Sci. Sport. Exerc. 27, 1292-1301 (1995)

14. Levine B, Stray-Gundersen J: "Living high-training low": effect of moderate-altitude acclimatization with lowaltitude training on performance. J. Appl. Physiol. 83, 102-112 (1997)

15. Levine BD, Stray-Gundersen J: Point: positive effects of intermittent hypoxia (live high: train low) on exercise performance are mediated primarily by augmented red cell volume. J. Appl. Physiol. 99, 2053-2055 (2005)

16. MacDougall JD, Hicks L, MacDonald R, McKelvie RS, Geen HJ, Smith, KM: Muscle performance and enzymatic adaptations to sprint interval training. J. Appl. Physiol. 84, 2138-2142 (1998)

17. Meeuwsen T, Hendriksen IJ, Holewijn M: Training-induced increases in sea-level performance are enhanced by acute intermittent hypobaric hypoxia. Eur. J. Appl. Physiol. 84, 283-290 (2001)

18. Millet GP, Roels B, Schmitt L, Woorons X, Richalet JP: Combining hypoxic methods for peak performance. Sports Med. 40, 1-25 (2010)

19. Morkeberg JS, Belhage B, Damsgaard R: Changes in blood values in elite cyclist. Int. J. Sports Med. 30, 130138 (2009)

20. Morton JP, Cable NT: Effects of intermittent hypoxic training on aerobic \& anaerobic performance. Ergonomics 48, 1535-1546 (2005)

21. Puype J, Van Proeyen K, Raymarkers JM, Delcicque L, Hespel P: Sprint Interval Training in hypoxia stimulates glycolytic enzyme activities. Med. Sci. Sports Exerc. 45, 2166-2174 (2013)

22. Rodriguez FA, Casas H, Casas M: Intermittent hypobaric hypoxia stimulates erythropoiesis and improves aerobic capacity. Med. Sci. Sports Exerc. 31, 264-268 (1999)

23. Roels B, Millet GP, Marcoux CJ, Coste O, Bentley DJ, Candau RB: Effects of hypoxic interval training on cycling performance. Med. Sci. Sports Exerc. 37, 138-146 (2005)

24. Roels B, Bentley DJ, Coste O, Mercier J, Millet GP: Effects of intermittent hypoxic training on cycling performance in well-trained athletes. Eur. J. Appl. Physiol. 101, 359-368 (2007)

25. Sanchis-Gomar F, Martinez-Bello VE, Domenech E, Nascimento AL, Pallardo FV, Gomez-Cabrera MC, Vina $\mathrm{J}$ : Effect of intermittent hypoxia on hematological parameters after recombinant human erythropoietin administration. Eur. J. Appl. Physiol. 107, 429-436 (2009)

26. Skinner J, McLellan T: The transition from aerobic to anaerobic metabolism. Res. Quart. Exerc. Sport 51, 234-248 (1980)

27. Truijens MJ, Toussaint HM., Dow J, Levine BD: Effect of high-intensity hypoxic training on sea-level swimming performances. J. Appl. Physiol. 94, 733-743 (2003)

28. Vallier JM, Chateaou P, Guezennec CY: Effects of physical training in a hypobaric chamber on the physical performance of competitive triathletes. Eur. J. Appl. Physiol. Occup. Physiol. 73, 471-478 (1996)

29. Wilber RL: Application of altitude/hypoxic training by elite athletes. J. Hum. Sports Exer. 6, 1-12 (2011)

30. Wood MR, Dowson MN, Hopkins WG: Running performance after adaptation to acutely intermittent hypoxia. Eur. J. Appl. Physiol. 6, 163-172 (2011)

31. Zoll J, Ponsot E, Dufour S, Doutreleau S, Ventura R, Vogt M, Fluck M: Exercise training in normobaric hypoxia in endurance runners III. Muscular adjustments of selected gene transcripts. J. Appl. Physiol. 100, 1258-1266 (2006) 